\title{
Sociedade em Rede e categorias de análise de interação: programação LOGO e aprendizagem de Matemática *
}

\author{
Daniela Stevanin Hoffmann ** \\ Léa da Cruz Fagundes ***
}

Resumo: Este artigo estuda as interações entre estudantes do curso de Licenciatura em Matemática da Universidade Federal do Rio Grande do Sul em uma proposta didática, apoiada na utilização de Tecnologias da Informação e Comunicação, fundamentada em princípios da Epistemologia Genética. Seguindo a metodologia de pesquisa do Laboratório de Estudos Cognitivos do Instituto de Psicologia (LEC/IP/UFRGS), foram definidas categorias para analisar os registros que indicaram um movimento de transição de uma postura passiva, receptora de informações, para uma postura ativa, produtora de conhecimento, na qual os graduandos foram desenvolvendo atitudes, habilidades e competências do perfil do sujeito da Sociedade em Rede. Os dados foram colhidos na Lista de Discussão de e-mail da disciplina Computador na Matemática Elementar. Acreditamos que essas categorias possam ser utilizadas no acompanhamento de situações de aprendizagem a distância e/ou que façam uso de Tecnologias Digitais.

Palavras-chaves: categorias de interação; aprendizagem de matemática; sociedade em rede; tecnologias da informação e comunicação.

\section{Network Society and analysis categories of interaction: LOGO programming and Mathematics learning}

Abstract: In this article, we study the interactions between students of the course of "Licenciatura em Matemática" of "Universidade Federal do Rio Grande Do Sul" in a didactic proposal supported in the use of Information and Communication Technologies and based on principles of Genetic Epistemology. Following the research methodology of "Laboratório de Estudos Cognitivos" of "Insituto de Psicologia" (LEC/IP/UFRGS) categories had been defined to analyze the registers that had indicated a movement of transition from a passive position, receiver of information, for an active position, producer of knowledge, in which the students had been developing attitudes, abilities and abilities of the profile of the subject of Network Society. Data had been harvested in the List of Discussion of the discipline "Computador na Matemática Elementar". We believe that these categories can be used in the accompaniment of distance learning situations and/or that make use of Digital Technologies.

Key-words: interaction categories; mathematics learning; network society; information technologies.

\section{Introdução}

Com o surgimento das Novas Tecnologias da Informação e Comunicação (NTICs), a produção de bens materiais foi atrelada à produção de conhecimento, atribuindo à sociedade um caráter dinâmico, reestruturando padrões de espaço e tempo. Castells (1999) aponta que estamos vivendo uma revolução tecnológica centrada nas Tecnologias da Informação (TI), a qual está remodelando a base material da sociedade. Essa nova lógica de organização é fruto e, ao mesmo tempo, é geradora do que Castells (1999) conceitua como rede: uma estrutura dinâmica, capaz de expansão ilimitada, que agrega indivíduos, grupos, empresas ou nações com interesses comuns. Cada componente da rede vive a dialética entre a autonomia e a dependência à rede a qual pertence podendo integrar mais de uma rede, com objetivos diferenciados, e promover a 
conectividade e a coerência entre elas, potencializando uma possível expansão. Essas redes articulam-se na economia global e informacional baseada na inovação, globalização e descentralização; na política desenvolvimentista voltada para a competitividade global; e na sociedade, mais especificamente, nas relações de trabalho voltadas para a flexibilidade e adaptabilidade das empresas e dos trabalhadores. Em suma, o desenvolvimento das TI e a (re)estruturação global e informacional configuram a nova Sociedade em Rede: caracterizada pela globalização das atividades econômicas, por sua forma de organização em redes e pelas flexibilidade e instabilidade de emprego e individualização - de capacidades, condições de trabalho e interesses - da mão-deobra.

Na Sociedade em Rede, o desenvolvimento das NTICs introduz, difunde e valoriza atividades relacionadas ao amplo acesso, tratamento e gerenciamento de informações, cada vez mais abundantes e diversificadas, formando um novo perfil de sujeito. Esse sujeito da Sociedade em Rede é requisitado a possuir, e a aprimorar constantemente, diferentes habilidades, atitudes e competências, tais como: detectar e formular problemas, pensá-los sob diferentes perspectivas e equacioná-los; buscar e implementar as melhores soluções; experimentar, testar e avaliar as soluções encontradas; contextualizar e questionar os caminhos escolhidos para solucionar desafios; operar com os conhecimentos, processá-los e integrá-los em novos sistemas de significação; e trabalhar em equipe, tendo disposição para ouvir, contribuir e produzir no e para o grupo.

Lévy (1999) enfatiza que uma parcela crescente da população já não tem como trabalho apenas uma execução repetitiva de tarefas prescritas, mas defronta-se com atividades complexas, nas quais a resolução inventiva de problemas, a coordenação dentro de equipes e a gestão de relações humanas ocupam lugares importantes. A produção, o aprendizado contínuo, a aquisição e a socialização de saberes é parte integrante das (novas) atividades profissionais. As mudanças sociais, que presenciamos e das quais fazemos parte, tornam o meio social mais exigente e competitivo. $\mathrm{O}$ conhecimento vem se estabelecendo como moeda de mercado e sinônimo de poder. Paradoxalmente, enquanto o conhecimento cresce em valorização, o sistema educacional sofre os efeitos de uma crise gerada por problemas, com os quais ainda não aprendeu a lidar, advindos dessa mesma valorização. Entretanto, as mudanças no âmbito educacional são lentas e a realidade ainda mostra uma escola de saberes fragmentados, desconexos e, até mesmo, contraditórios.

No que diz respeito ao processo de ensino-aprendizagem de Matemática, suas orientações metodológicas e seus objetivos vêm passando por inúmeras críticas e algumas mudanças. Existe um razoável consenso de que o ensino-aprendizagem dessa disciplina não pode ser limitado a um processo de memorização de regras e técnicas, mas deve enfatizar a construção de conhecimentos e a resolução de problemas, além do domínio dos conceitos básicos historicamente definidos. Entretanto, de maneira geral, os problemas identificados, na Educação Matemática, por Dienes (1970), Papert (1980) e Carraher (1989), dentre outros autores, continuam sendo repetidos e perpetuados, ou seja, a falta de compreensão das estruturas e dos conceitos matemáticos, a repetição de exercícios, a exploração de conceitos sem significação ou aplicação. Enfim, mantém-se a reprodução de uma Matemática Escolar desvinculada da realidade dos estudantes e de seus interesses. Salvo alguns professores, atentos ao processo de aprendizagem de seus alunos, a grande maioria segue o modelo da exposição de conteúdos, contrários à proposição dos Parâmetros Curriculares Nacionais (2002), de que o Ensino Médio deve ser uma etapa que possibilite a aquisição de conhecimentos ligados à preparação científica e à capacidade de utilização de diferentes tecnologias. Isso deve ocorrer de modo a propiciar ao aluno a possibilidade de desenvolver "a capacidade de pesquisar, 
buscar informações, analisá-las e selecioná-las" e "a capacidade de aprender, criar, formular, ao invés do simples exercício da memorização" (PCN, 2002, p. 16).

Ao contrário da simples reprodução de procedimentos e do acúmulo de informações, alguns professores de Matemática concordam que devem possibilitar o desenvolvimento de competências de observação e análise, de estabelecimento de relações, de comunicação e argumentação e de validação e defesa de processos e idéias, além de estimular diferentes formas de raciocínio, intuição, indução e dedução e a estimativa. A proposta didático-pedagógica adotada na disciplina de Computador na Matemática Elementar (CME) do curso de Licenciatura em Matemática (LICMAT) do Instituto de Matemática da Universidade Federal do Rio Grande do Sul (IMAT/UFRGS), em 2005/1, buscou o desenvolvimento das atitudes, habilidades e competências do sujeito da Sociedade em Rede, criando oportunidades de exploração de conceitos matemáticos, tecnológicos e sócio-interativos a partir da utilização de NTICs (interações na rede virtual e com software). No acompanhamento desse desenvolvimento, foram estruturadas três categorias de análise.

\section{Técnicas e Materiais}

Disciplina do primeiro semestre, CME faz uma retomada de conceitos matemáticos da Educação Básica a partir da utilização do software SuperLogo (SLOGO). Segundo Garcia (1999), no LICMAT, o objetivo do uso do SLOGO é possibilitar que os estudantes sejam condutores da sua própria aprendizagem, por meio de atividades de investigação, pela criação de seus próprios desafios, ensaios de estratégias e análise de seus próprios erros, ou seja, "a ênfase está na parte do trabalho científico em que se dá o conhecimento novo, dando oportunidade do usuário perceberse como alguém faz ciência" (p. 223). Assumi essa disciplina durante os dois anos de contrato como professora substituta junto ao IMAT/UFRGS (2003/2 - 2005/1).

A proposta de utilização do ambiente LOGO, segundo Papert (1980), um de seus criadores, fundamentado na Epistemologia Genética, indica, entre outros aspectos, que o professor deve ressaltar a existência de várias possíveis soluções para um problema e permitir que o aluno as encontre por si próprio, evitando apresentar soluções prontas e deve provocar o aluno a pensar sobre o que faz, questionando suas estratégias e hipóteses sobre o que está acontecendo e sobre o que ele imagina que acontecerá a seguir. Assim, para aproximar a disciplina da proposta de uso do software, as atividades de CME visavam à exploração dos conceitos e dos recursos do programa. O trabalho com ambiente virtual dispôs de uma Lista de Discussão de e-mail, buscando aumentar as trocas entre os alunos, ou seja, a cooperação entre os pares na investigação de problemas e na elaboração de soluções.

Atualmente existem diversas versões de software com Linguagem LOGO (LLOGO). O SuperLogo 3.0 (SLOGO), versão utilizada na disciplina CME, é gratuito disponível na Internet - e funciona em ambiente Windows (Figura 1). O SLOGO é um software no qual o usuário comanda a Tartaruga e constrói e manipula imagens, números, palavras, listas, listas de listas, matrizes, etc., com a programação em LLOGO que implementa. A Tartaruga representa, na tela do computador, as ordens dadas pelo usuário e estas podem ser consideradas como uma representação do seu pensamento.

Segundo Papert (1980), essa Tartaruga tem o propósito de ser "fácil de programar e boa para se pensar" (p. 42), pois o processo de programá-la começa por refletir sobre como nós fazemos o que gostaríamos que ela fizesse. Por exemplo, para fazer a Tartaruga desenhar um quadrado, a pessoa pode andar sobre um quadrado imaginário e descrever o que está fazendo, expressando a "geometria do corpo" pela linguagem de programação da Tartaruga. Dessa forma, ensiná-la a agir e, até mesmo, a "pensar", possibilita a reflexão sobre nossas próprias ações e pensamentos.

V. $4 \mathrm{~N}^{\circ} 1$, Julho, 2006 


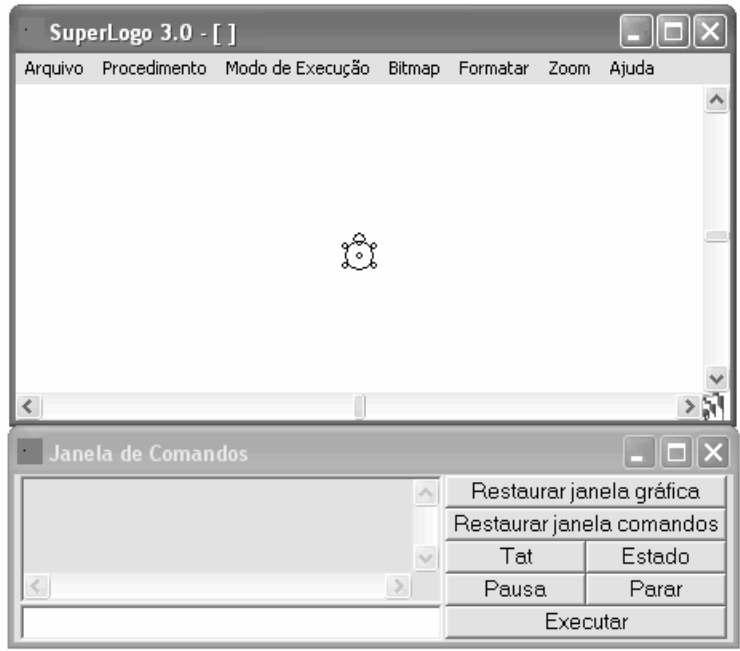

Figura 1: SuperLogo 3.0 para Windows.

Busca-se, no uso da LLOGO, a exploração de diferentes soluções para um problema, isto é, da estratégia que se escolhe para resolvê-lo. Sob esse aspecto, programar passa a ser uma atividade metacognitiva, que possibilita que os alunos discutam e pensem sobre suas próprias ações e sobre como aprendem. Assim, cada uma das atividades propostas em CME têm como propósito centrar a atenção dos alunos sobre os vínculos entre o problema, o método de solução adotado e o procedimento elaborado para chegar à sua representação e a sua solução informática.

$\mathrm{Na}$ busca pelo algoritmo de representação da solução do problema, os graduandos passam pela representação verbal da tarefa, conversando sobre possíveis soluções, pela representação gestual, transformando o problema abstrato em um conjunto de subproblemas ligados à motricidade, por representações gráficas, desenhando, fazendo esboços, cálculos, manipulação e deduções de fórmulas e, por fim, para a representação informática, que resulta em um algoritmo subjacente à estratégia criada. Em síntese, o computador, associado ao conhecimento da LLOGO, permite que a interpretação de um problema e a estratégia escolhida sejam traduzidas em uma seqüência de comandos, isto é, em um procedimento, que além de fornecer a resposta ao desafio inicial permite vislumbrar a estratégia de resolução, os raciocínios e os conceitos utilizados.

Acreditando que o conhecimento surge da interação do sujeito com o objeto a conhecer, da dúvida, da busca por novas alternativas para apropriar-se dele, surgiu a necessidade de trocas de pontos de vista, de estratégias e de hipóteses formuladas. Assim, além das aulas de CME, nas quais ocorriam as trocas presenciais, foi disponibilizada uma Lista de Discussão em ambiente digital ${ }^{1}$. Um dos propósitos de criar essa Lista foi possibilitar uma espécie de ajuda on line, mesmo que assíncrona, na qual cada graduando pudesse expor as soluções que encontrasse para as atividades desenvolvidas, formando uma espécie de repositório de programações. Segundo Fagundes "et al" (2000), quando os alunos confrontam-se com outros pontos de vista, ocorre um movimento de voltar-se para a sua produção. Assim, poderiam repensar suas posições frente às atividades, mudando-as, ampliando-as ou fortalecendo seus próprios argumentos.

De acordo com Grize (1993), o pensamento diário, informal, é expresso por meio de discursos de um sujeito que se dirige a outros, todos situados no espaço e no tempo e inseridos em uma cultura. Grize (1993) afirma que o discurso é um comportamento verbal que permite a observação das representações cognitivas, partindo do princípio de que qualquer discurso é elaborado a partir do modelo mental de um 
sujeito sobre uma realidade específica, isto é, a partir de uma representação da organização dos objetos de pensamento e das articulações estabelecidas entre eles. Assim, outro propósito, para criar esse espaço de interação, foi a possibilidade de acompanhar e compreender o processo pelo qual o sujeito chegava a resposta para uma atividade, visto que as programações eram divulgadas, comentadas e questionadas, inclusive, pelos próprios discentes.

Considerou-se, também, o fato de que os pedidos por explicações e justificativas para suas respostas poderiam levar o sujeito a refletir sobre a questão, fazendo transparecer seu nível de compreensão do problema e dos conceitos envolvidos, provocando um conflito cognitivo, ou seja, situações que gerassem divergências entre as hipóteses e as explicações formuladas e as propriedades do objeto. Esse conflito provocaria, no raciocínio do sujeito, perturbações suscetíveis de serem fontes de (re)construção de conceitos, isto é, de desenvolvimento.

A abordagem de Grize (1996) quanto aos processos de comunicação foi escolhida para estruturar parte da análise porque contempla um dos aspectos do perfil do sujeito da Sociedade em Rede. O autor fornece suporte para estudar características do trabalho em equipe: a disposição para ouvir, contribuir e produzir no e para o grupo. De acordo com Grize (1996), frente a uma argumentação $\boldsymbol{A}$, o receptor tem duas possíveis reações: ou aceita a argumentação sem resistência alguma ou a põe em dúvida perguntando "por que $\boldsymbol{A}$ ?". No primeiro caso, a argumentação $\boldsymbol{A}$ pode servir de acervo para a continuação do diálogo; no segundo, o emissor precisará responder a dúvida do destinatário.

Adaptando tal teoria (Grize, 1996), criamos a primeira categoria de análise relativa à postura dos sujeitos envolvidos na comunicação em rede. A ação dos destinatários, em relação ao tema/conteúdo das mensagens, foi subcategorizada como:

- recepção: quando determinada mensagem $\boldsymbol{A}$ for, simplesmente, respondida de forma "casual", despreocupada com o assunto da mensagem e/ou não relacionada à argumentação do emissor; ou quando o receptor fizer menção ao assunto da mensagem $\boldsymbol{A}$, porém, sem evidências de que compreendeu seu conteúdo .

- aceitação: quando certa mensagem $\boldsymbol{A}$ for respondida, dando continuidade ao assunto, mostrando compreensão e apropriação suficiente para questionar ou opôr-se a seu conteúdo. Determina-se que o questionamento e/ou o posicionamento contrário são necessários para que haja aceitação: o assunto foi lido, assimilado e questionado.

- adesão: quando uma mensagem $\boldsymbol{A}$ for respondida por um sujeito que concorde com seu conteúdo e acrescente seu posicionamento. A concordância, o ser convencido é necessário para que se possa constatar adesão do sujeito e determina-se que isso será evidenciado por um discurso que expresse esse conteúdo agregando informações.

Outro aspecto do perfil do sujeito da Sociedade em Rede estudado refere-se ao raciocínio lógico necessário para operar com conhecimentos diversos, processá-los e integrá-los em novos sistemas de significação. Para esse propósito, escolheu-se a teoria desenvolvida por Piaget e Garcia no livro Hacia una Lógica de Significaciones (1989) como segunda categoria. Segundo esses autores, existe uma Lógica de Significações fundamentada nas implicações entre significações ou entre ações. Essas implicações são inferências atribuídas às propriedades, aos objetos, aos conceitos e às próprias ações. A Lógica das Significações tem seu começo na passagem progressiva das coordenações das ações às composições de antecipações. A implicação de ações, a partir de antecipações, é suscetível a julgamentos de veracidade ou falsidade e constitui, assim, 
uma lógica no sentido comum do termo. A elaboração das relações construídas pelo sujeito apóia-se nas implicações significantes. Estas podem ser classificadas em três diferentes tipos, que formam o nosso segundo grupo de subcategorias:

- implicação local: a significação das ações é determinada pelo que pode ser registrado do objeto empírico a partir das suas propriedades e do seu contexto particular imediato.

- implicação sistêmica: insere as implicações em um sistema de relações no qual as generalizações e as propriedades não diretamente observáveis começam a ser percebidas, não apenas do objeto em si, mas do que pode ser dito dele ou da ação sobre ele. Embora as implicações ainda não sejam justificáveis e haja certa confusão entre generalidade e necessidade, as inferências consideram antecipações que superam o constatável e fundamentam-se em implicações necessárias.

- implicação estrutural: refere-se às composições internas de estruturas já construídas, dando as justificativas que permitem realizá-las. O sujeito passa a compreender as razões dos fatos gerais observados e a identificar as relações necessárias e diferenciá-las das suficientes. Há distinção entre generalidade e necessidade.

A identificação de tais implicações significantes permite acompanhar um processo de conceituação, pois, de acordo com a Epistemologia Genética, um conceito se forma a partir das transformações dos sistemas de significação do sujeito, num processo contínuo de auto-regulação e coordenações sucessivas ativadas por desequilíbrios nesses sistemas. Observando as falas dos sujeitos da pesquisa, durante suas trocas na Lista de Discussão, não podemos concluir que, pelo simples fato de usar um termo que designa um conceito, o sujeito tenha a construção conceitual correspondente já elaborada. As palavras podem representar os conceitos, mas é a partir das relações construídas na atribuição de significado que se pode identificar a apropriação de um conceito.

Focando no perfil do sujeito da Sociedade em Rede, mais uma categoria foi estabelecida com quatro subcategorias de análise que identificam as diferentes abordagens dos sujeitos na construção das argumentações em relação às situaçõesproblema discutidas:

- vida acadêmica: são as mensagens enviadas pelos graduandos referindo-se à vivência no curso LICMAT/UFRGS;

- $\quad$ identificação de problemas: quando um sujeito enviar uma mensagem que aborde uma dúvida, seja sobre o funcionamento da Lista ou da disciplina, ou referente a alguma atividade de $\mathrm{CME}$, ou uma questão sobre programação em LLOGO;

- $\quad$ sugestão de soluções: quando um graduando apresentar uma possível solução a uma dúvida levantada na Lista, em uma mensagem anterior;

- $\quad$ depuração: quando, além da identificação de um problema ou da apresentação de uma solução, ocorrer uma argumentação sobre sua validade, praticidade, estética ou entendimento.

\section{Resultados e Discussão}

A partir das categorias estruturadas, foi feita a análise de parte das mensagens da Lista de Discussão da disciplina CME. O intuito foi, nos extratos de mensagens selecionados, analisar a postura dos sujeitos frente à oportunidade de se tornarem ativos em seus processos de aprendizagem e identificar características análogas ao perfil do sujeito da Sociedade em Rede. Exemplificaremos a análise realizada a partir da 
representação da rede de conversação estabelecida em um dos Blocos de Mensagens da Lista $^{2}$, destacando as interações entre os sujeitos e entre os conteúdos das mensagens.

Quadro 1 - Categorias e subcategorias de análise

\begin{tabular}{|l|l|}
\hline Categorias & Subcategorias \\
\hline 1. Posturas dos sujeitos na comunicação em rede & $\begin{array}{l}\text { Recepção } \\
\text { Aceitação } \\
\text { Adesão }\end{array}$ \\
\hline 2. Relações conceituais construídas pelos sujeitos & $\begin{array}{l}\text { Implicação Local } \\
\text { Implicação Sistêmica } \\
\text { Impliçãão Estrutural }\end{array}$ \\
\hline 3. Construção das argumentações & $\begin{array}{l}\text { Vida acadêmica } \\
\text { Identificação de Problemas } \\
\text { Sugestão de soluções } \\
\text { Depuração }\end{array}$ \\
\hline
\end{tabular}

A Categoria 1, Posturas dos sujeitos na comunicação em rede, foi adaptada da teoria de Jean-Blaise Grize (1996) para analisar aspectos do trabalho em equipe, isto é, a disposição para ouvir, contribuir e produzir no e para o grupo; a Categoria 2, Relações conceituais construídas pelos sujeitos, oriunda da Lógica das Significações de Piaget e Garcia (1989), analisa o raciocínio lógico para operar com conhecimentos diversos, processá-los e integrá-los em novos sistemas de significação; a Categoria 3, Construção das argumentações, criada para a pesquisa, analisa as diferentes abordagens na construção de argumentações em relação às situações-problema discutidas, contemplando as habilidades, atitudes e competências do sujeito da Sociedade em Rede que ainda não haviam sido respaldadas pelas categorias anteriores.

A análise segundo as categorias descritas, será representada por parte das mensagens do Bloco $26^{3}$, que tem sua rede de conversação representada na Figura 2.

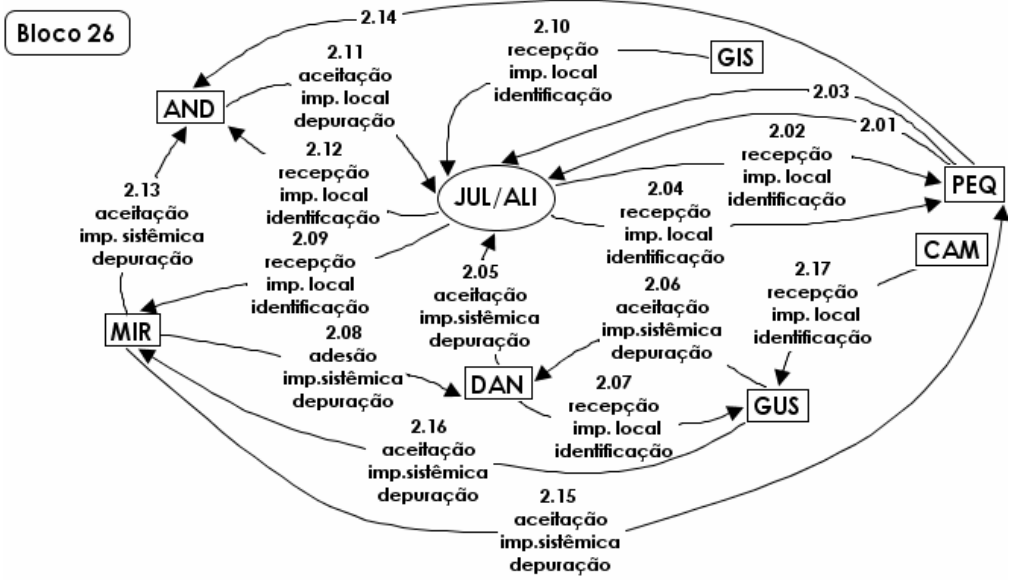

Figura 2 - Bloco de Mensagens 26 : trocas assíncronas no período de 30/05/05 a 05/06/05

Mensagem 1 (JUL/ALI): Gente, eu e a ALI descobrimos que a Tat é doida!!!! Quando a gente coloca pf $\cos 90^{\circ}$ ela não anda... Ou seja... $\operatorname{Cos} 90^{\circ}=0$ Massssssssssssssss botando pf $100 / \cos 90^{\circ}$ ela anda infinito!!! Alguém pode nos explicar isso?? Obrigada...

Mensagem 2.01 (PEQ): Vocês já pediram para a tartaruga escrever quem é o cos $90^{\circ}$ ?

Mensagem 2.02 (JUL/ALI): daniiiiiii.. O q q significa isso????

lescreva cos $906.1257422745431 \mathrm{e}-17$ l

acho q essa tartaruga eh locaaa ou a gente nao sabe mais nada de trigonometria...

Mensagem 2.03 (PEQ): que número é esse? 6.1257422745431e-17 ? A pergunta é: o que siginifica "e-17" ?? Olha só o que a tartaruga faz: lescreva 10e-1 1 ll lescreva 10e-2 0.11 O que a tartaruga faz com aquele "e-Número" ??? Se entendermos isso, entenderemos 
que número é 6.1257422745431e-17

Mensagem 2.04 (JUL/ALI): ai daniiii.. eu e a JUL nao entendemos..

lescreva 10e-1 1 l lescreva 10e-2 $0.11 \quad$ lescreva 10e-3 0.011

aqui parece que a tat escreve $10 / 10^{1}, 10 / 10^{2}$ e $10 / 10^{3}$ mas o q significa e-numero???

Mensagem 2.05 (DAN): É impressão minha ou "e+número" significa $10^{\wedge}$ número(positivo) e "e número" significa $10^{\wedge}$ número(negativo)? Isso quer dizer que ela toma para tangente de $90^{\circ}$ um número muito grande, e para co-seno de $90^{\circ}$ um número muito pequeno?

Mensagem 2.06 (GUS): bah nao acredito... q locura... por acaso isso significa que cos $90^{\circ}$ não é zero, mas sim algo muuuito menos q 1 ??? pelo q entendi $6.1257422745431 \mathrm{e}-17=$ 6.1257422745431 x $10^{\wedge}-17$ ou seja 0 cos de $90^{\circ}$ é 0,000000000000000061257422745431 ???????

Mensagem 2.08 (MIR): Pois é... muito estranho... bom, alguém a programou, e esse alguém deve ter tido um motivo pra aproximar o cos $90^{\circ}$ de zero, mas sem chegar lá... de repente, se fosse zero, isso ia fazê-la empacar em muitas coisas...

A mensagem 1, escrita por JUL/ALI(1) busca, na Lista, ajuda para um problema identificado na realização de uma atividade proposta na disciplina. Por ser a primeira mensagem a categoria 1 não é aplicada. $\mathrm{Na}$ análise da categoria 2 , a subcategoria identificada foi a implicação local, pois a significação das ações é determinada pelo registro das propriedades e do contexto particular imediato do objeto empírico. Na análise da categoria 3, obtém-se a subcategoria de identificação de problemas, uma vez que os alunos lançam uma questão sobre programação em LOGO. Em retorno à mensagem, PEQ faz um questionamento, instigando a exploração do problema e a formulação de hipóteses. A mensagem 2.02, dentro da categoria 1, caracteriza-se como uma recepção, pois os graduandos fazem menção ao assunto da mensagem, porém, não se tem evidência de que o conteúdo foi compreendido. A análise novamente aponta para uma implicação local e uma identificação de problemas, pelos mesmos argumentos utilizados anteriormente.

Novamente, PEQ questiona os licenciandos, buscando conduzir a compreensão da situação-problema colocada. Os alunos JUL/ALI, porém, mantêm sua postura passiva, aparentando não compreender o questionamento, apenas observando os atributos imediatos do objeto e restringindo-se a identificar o problema, sem formular possíveis explicações ou soluções para ele. É na seqüência da interação, quando outro sujeito intervém, que o problema começa a ser analisado teórica e criticamente. $\mathrm{Na}$ mensagem 2.05, DAN mostra sua aceitação em relação às mensagens anteriores, pois dá continuidade ao assunto, mostrando que o compreendeu, que se apropriou de seu conteúdo o suficiente para questioná-lo. Foi categorizada uma implicação sistêmica, uma vez que o sujeito insere suas implicações em um sistema de relações no qual as generalizações e as propriedades não diretamente observáveis começam a ser percebidas, não apenas do objeto em si, mas do que pode ser dito dele ou da ação sobre ele. Entretanto, essas implicações ainda não são justificáveis. A categoria 3 foi identificada na forma de uma depuração, pois o sujeito argumenta sobre a validade e o entendimento do problema. A mensagem 2.06 repete o padrão de aceitação, implicação sistêmica e depuração. A mensagem 2.08, caracteriza a adesão, pois MIR concorda com o conteúdo discutido e acrescenta seu posicionamento. $\mathrm{O}$ sujeito expressa o assunto discutido de uma nova forma, agregando novas informações. Repetem-se a implicação sistêmica e a depuração.

\section{Conclusões}

O Bloco analisado nos permite fazer uma aproximação entre o perfil buscado e as subcategorias identificadas. Conforme podemos visualizar na Figura 3, à medida que o sujeito modifica sua postura, transformando-se de sujeito receptor de informações a 
produtor de conhecimento, na experiência explorada de aprendizagem de Matemática, aproxima-se do perfil de sujeito da Sociedade em Rede.

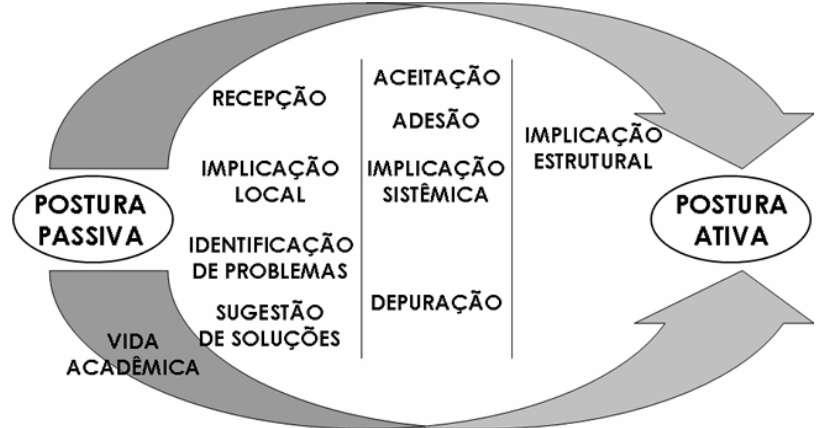

Figura 3 - Transição da postura passiva para a ativa: tornar-se sujeito da SR.

A partir da situação analisada, acredita-se ter dado evidências do quanto a utilização de NTICs na aprendizagem de Matemática possibilita o desenvolvimento de atitudes, habilidades e competências valorizadas socialmente. Investigou-se uma forma de utilizá-las para auxiliar nos processos de aprendizagem e no desenvolvimento de uma postura ativa na construção de conhecimento matemático, social e inter-relacional. A ênfase foi colocada na atividade, na reflexão e na argumentação do próprio sujeito, interagindo numa comunidade em rede, que foram registradas através de discursos na Lista de Discussão de CME. Nesta situação, foi possível identificar e categorizar suas posturas na comunicação em rede virtual, as relações que eles estabeleciam entre os conceitos que discutiam e a construção das argumentações que realizavam.

$\mathrm{Na}$ análise que nos conduziu a essa categorização, encontramos relações entre o perfil do sujeito da Sociedade em Rede e as atitudes dos sujeitos desta pesquisa. Os discentes viveram a necessidade de detectar e formular problemas, pensá-los sob diferentes perspectivas e equacioná-los; de buscar e implementar as melhores soluções; de testar e avaliar as soluções encontradas; de contextualizar e questionar os caminhos escolhidos para solucionar desafios; de operar com os conhecimentos, processá-los e integrá-los em novos sistemas de significação; e de saber trabalhar em equipe, criando disposição para ouvir, contribuir e produzir no e para o grupo.

Isso foi registrado na análise nas transposições entre as subcategorias de recepção para aceitação e/ou adesão; de implicação local para a sistêmica (e para estrutural); e da conversa sobre a vida acadêmica para a identificação de problemas e sugestão de soluções e para a depuração das situações-problema que os próprios alunos levantavam e fomentavam. Assim, percebeu-se que os alunos passaram a manifestar-se mais ativamente frente aos novos desafios provocados por desequilíbrios cognitivos que eles mesmos desencadeavam.

Acredita-se que essa maneira de categorizar as condutas dos sujeitos na Lista de Discussão pode contribuir para estudos referentes a trocas virtuais, uma vez que esses estudos ainda se restringem ao tratamento de freqüências estatísticas, não enfatizando as construções conceituais. Essa categorização pode ser aplicada, não exclusivamente para conceitos matemáticos, mas para conhecimentos sociais e culturais de uma forma ampla. Uma perspectiva de continuação para esse trabalho é a utilização das categorias aqui desenvolvidas na avaliação de cursos de Educação a Distância (EAD), tanto no acompanhamento do desenvolvimento dos discentes quanto dos docentes e da estrutura e da operacionalização de determinado curso de EAD.

\section{Notas}

* Artigo extraído da dissertação de mestrado "Aprender Matemática: tornar-se sujeito da Sociedade em Rede", realizada pela autora do artigo, no Programa de Pós-Graduação em Psicologia Social e 
Institucional, Instituto de Psicologia, Universidade Federal do Rio Grande do Sul (PPGPSI/UFRGS).

** Licenciada em Matemática, mestranda do PPGPSI/UFRGS. E-mail: danielah@ psico.ufrgs.br

*** Orientadora e docente do PPGPSI/UFRGS e do Programa de Pós Graduação em Informática na Educação (PGIE), Universidade Federal do Rio Grande do Sul (PGIE/UFRGS), Coordenadora de Pesquisa do Laboratório de Estudos Cognitivos (LEC/UFRGS), Doutora em Psicologia. E-mail: leafagundes@vortex.ufrgs.br

1 slogo@psico.ufrgs.br (http://murphy.psico.ufrgs.br/cgi-bin/mailman/listinfo/slogo)

2 As mensagens da Lista foram agrupadas em Blocos de acordo com o assunto/conteúdo das mensagens, agregando aquelas que poderiam ser identificadas como uma conversa.

3 Os sujeitos da pesquisa consentiram com o estudo e divulgação de sua produção coletada durante a pesquisa. Suas identidades estão preservadas pela substituição de seus nomes por códigos formados com três letras de seus nomes (não necessariamente as três primeiras). A professora é identificada pelo código PEQ (pesquisadora) e suas mensagens não são analisadas.

\section{Referências}

BRASIL. Parâmetros Curriculares Nacionais: Ensino Médio. Secretaria de Educação Média e Tecnológica. Brasília, DF, MEC/Semtec, 2002.

CARRAHER, T. N. Sociedade e Inteligência. São Paulo: Cortez, 1989.

CASTELLS, M. A Sociedade em Rede (Era da Informação: Economia, Sociedade e Cultura; v. 1). São Paulo: Paz e Terra, 1999.

DIENES, P. Z. Aprendizado Moderno da Matemática. Rio de Janeiro: Zahar, 1970.

FAGUNDES, L. da C. \& MAÇADA, D. L. \& SATO, L. S. Aprendizes do futuro: as inovações começaram!. Brasília: Estação Palavra, 2000.

GARCIA, V. C. Profissionalização do professor de matemática. 1999. Tese (Doutorado em Educação) - Programa de Pós-Graduação em Educação, Pontifícia Universidade Católica do Rio Grande do Sul, Porto Alegre, 1999.

GRIZE, J. B. Lógica Natural e Comunicação. PUF: Paris, 1996.

Lógica Natural e Representações Sociais. Disponível em: <http://www.psr.jku.at/PSR1993/2_1993Grize.pdf>. Acesso em: 02 mai. 2005.

JURKIEWICZ, S. Matemática e Informática: quem precisa de quem? Disponível em: $<$ http://www.tvebrasil.com.br/salto/boletins2005/mnp/tetxt4.htm>. Acesso em: 15 jul. 2005.

LÉVY, P. Cibercultura. São Paulo: Ed. 34, 1999.

PAPERT, S. LOGO: Computadores e Educação. São Paulo: Brasiliense, 1980.

PIAGET, J. \& GARCIA, R. Hacia una Lógica de Significaciones. México: Gedisa, 1989.

PIAGET, J. A Equilibração das Estruturas Cognitivas: Problema Central do Desenvolvimento. Rio de Janeiro: Zahar, 1975. 